\title{
Risk factors of delirium in elderly patients with hip fracture
}

\author{
Sunee Suwanpasu ${ }^{\mathrm{a}}$, Susan Grinslade ${ }^{\mathrm{b}}$, Yow-Wu B. Wu ${ }^{\mathrm{b}}$, Davina Porock ${ }^{\mathrm{b}}$ \\ ${ }^{a}$ Nursing department, King Chulalongkorn Memorial Hospital, Bangkok, Thailand, ${ }^{b}$ University at \\ Buffalo, School of Nursing, New York 14214, United States
}

\begin{abstract}
Background: Delirium is a leading cause of death and disability in the elderly with hip fracture. Identifying reliable risk factors for delirium is critical to support optimal outcomes for prevention and reducing delirium.

Objective: To quantify the reported factors associated to delirium for patients with hip fracture.

Methods: Electronic databases were searched (including Medline, Pub Med, CINAHL, EMBASE, Evidence Based Medicine Reviews, Cochrane Review, Web of Science, and PsycINFO) to identify all studies, published in English language that evaluated the risk factors of delirium hospitalized people with hip fracture. Two reviewers independently assessed methodology quality and extracted relevant data. The data from the included studies were summarized, and pooled estimates were calculated for 12 risk factors.

Results: Thirty-seven studies were included in the review and 25 in the meta-analysis. The incidence of delirium was $32.4 \%(95 \%$ confidence interval $[\mathrm{CI}]=25.9 \%-39.5 \%)$. Six predisposing and four precipitating factors predicted delirium among older patients with hip fracture confirmed. The predisposing factors included advanced age $(\mathrm{ES}=1.06,95 \% \mathrm{CI}=1.03-1.09)$, male sex $(\mathrm{ES}=1.34,95 \% \mathrm{CI}=1.08-1.68)$, impairment of cognition $(\mathrm{ES}=2.91$, $95 \% \mathrm{CI}=1.91-4.42)$, and function $(\mathrm{ES}=1.75,95 \% \mathrm{CI}=1.39-2.2)$, comorbidity $(\mathrm{ES}=1.59,95 \% \mathrm{CI}=1.30-1.96)$, and health problems $(\mathrm{ES}=2.64,95 \% \mathrm{CI}=2.04-3.42)$. Precipitating factors were hypo- or hypernatremia $(\mathrm{ES}=1.73$, $95 \% \mathrm{CI}=1.14-2.64)$, depression $(\mathrm{ES}=4.07,95 \% \mathrm{CI}=1.95-8.49)$, more than three prescribed drugs $(\mathrm{ES}=1.28$, $95 \% \mathrm{CI}=1.10-1.49)$, and drugs including opioids $(\mathrm{ES}=2.13,95 \% \mathrm{CI}=1.42-3.18)$ and anticholinergic agents $(\mathrm{ES}=2.10,95 \% \mathrm{CI}=1.60-2.75)$.

Conclusion: This meta-analysis result provides evidence that these risk factors have a significant impact on delirium in elders with hip fracture during hospitalization. Developing formal screening, and effective preventive and management strategies for delirium is important.
\end{abstract}

Keywords: Delirium, elderly, hip fracture, risk factors, systematic review

Delirium is a severe neuropsychiatric syndrome that is common and serious in older patients with hip fracture. A systematic review that identified 12 studies of interventional and analysis of pathogenic factors of postoperative delirium for hip fracture found that the occurrence of delirium varied between $16 \%$ and $62 \%$ [1]. Delirium is defined conceptually as "a disturbance of consciousness with inattention accompanied by a change in cognition or perceptual disturbance that develops over a short period of time (hour to days) and fluctuates over time" [2]. Episodes of delirium are associated with longer hospital stays and greater morbidity and mortality [3], cause considerable distress to patients and families, and is expensive [4].

Correspondence to: Davina Porock, University at Buffalo, School of Nursing, New York 14214, United States. E-mail: dporock@buffalo.edu
A useful predictive model for the development of delirium in elderly hospitalized patients [5] suggests that delirium is precipitated when the sum of predisposing and precipitating factors crosses a certain threshold. In such a model, the greater the predisposing factors, the fewer precipitating factors are required to initiate delirium [6]. This would explain why elderly hip fracture patients develop delirium in the face of stressors that are much less severe than those that can cause delirium in healthy adults. Understanding the predisposing and precipitating factors in cases of delirium provides the critical first step to identifying patients at high risk of developing the condition and for developing effective preventive and management strategies.

Systematic reviews have assessed studies investigating risk factors in medical and surgical patients. The reviews are limited by variation in quality 
and heterogeneity of the constituent studies [7], 84.4\% of the evidence was obtained from observational studies or expert opinions [8]. Thus, convincing data to prepare guidelines for prevention or attenuation of delirium associated with hip fracture is insufficient. Our objectives are to complete a systematic review and meta-analysis of the incidence of delirium in elderly patients with hip fracture, and risk factors for delirium during hospitalization.

\section{Materials and methods}

\section{Data sources and search strategy for identification} of studies

We searched databases for primary research published in English, from 1990 to 2012. An electronic database search was carried out using the following databases: Medline, Pub Med, CINAHL, EMBASE, Evidence Based Medicine Reviews, Cochrane Review, Web of Science, and PsycINFO. We also searched the studies from references of full-text articles. Duplicates were removed. We excluded research published before 1990 because of the different names used to define and describe delirium. Searches were undertaken using keywords including 'delirium', 'acute confusion', 'cognitive dysfunction', 'decline in cognitive function', 'hip fracture', 'femoral neck fracture', 'intertrochanteric fracture', and 'subtrochanteric fracture' and an English language restriction was applied. The Preferred Reporting Items for Systematic Reviews and Meta-Analysis (PRISMA) guidelines [9] were followed and fulfilled in this review.

\section{Criteria for considering studies}

PICO specifies patients selection, intervention, comparison, and outcomes [10]. This definition then determined criteria for including articles in the analysis. Two reviewers assessed the studies independently using the following inclusion criteria:

1. The majority of study participants were patients (aged 60 years or over) who sustained a hip fracture during hospitalization.

2. The factors included risk factors of delirium, pathogenic factors of delirium predictors of delirium, precipitating factors, and predisposing factors of delirium could have started preoperatively and postoperatively. Incidence of delirium also was included.

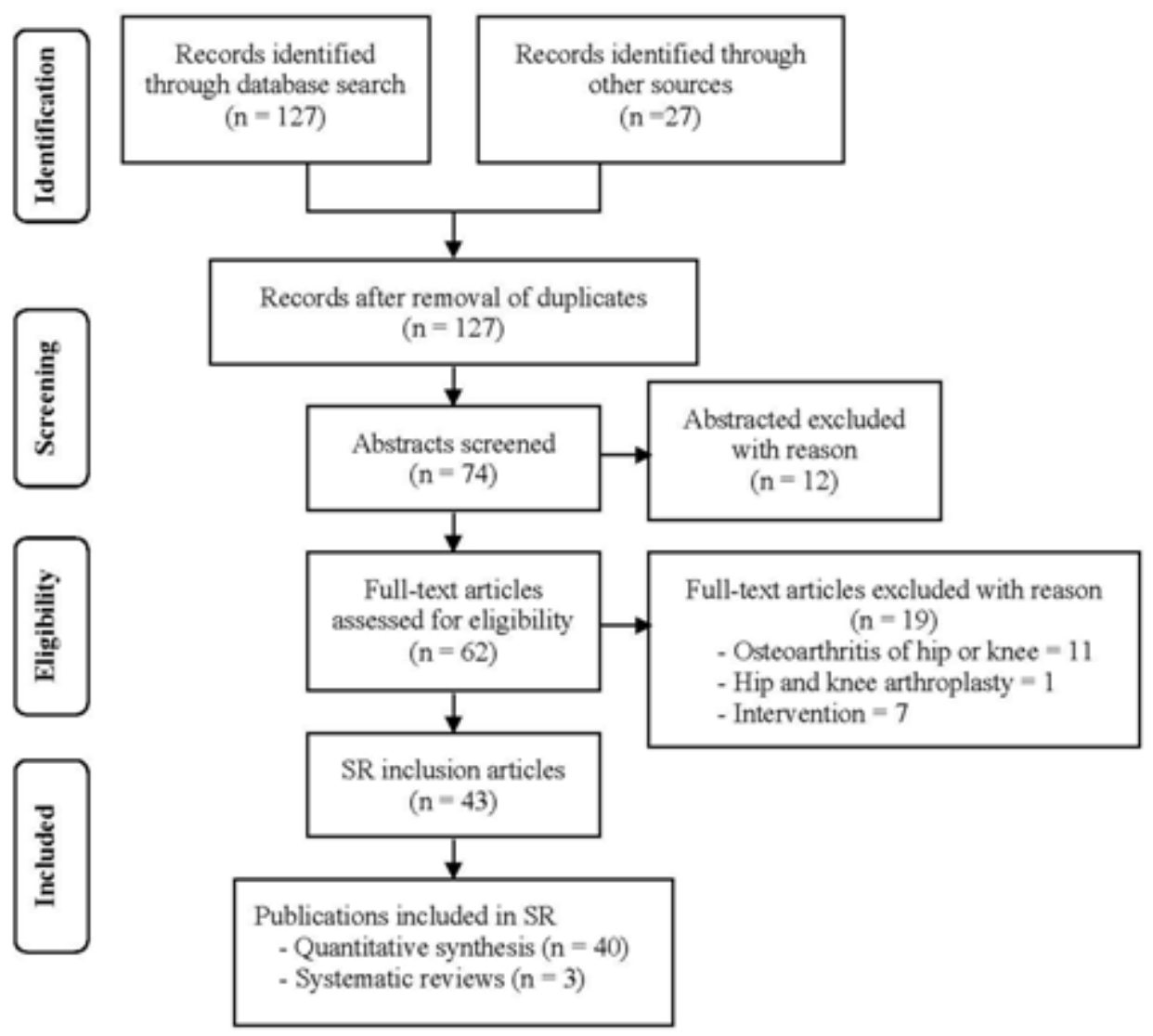

Figure 1. PRISMA flow diagram 
3. Delirium outcome pertaining to patients with history of risk factors, pathogenic factors or predictors was compared with those with no history of these factors.

4. Outcomes reflecting incidence, duration and severity of delirium, acute confusion, cognitive dysfunction, and decline in cognitive dysfunction were reported.

\section{Data collection and quality assessment}

All of the steps were conducted independently by 2 reviewers (SS and DP). The full texts of fifty articles were read and examined independently by two authors and there was consensus that twelve articles did not meet the inclusion criteria and they were eliminated. The methodological quality of the included articles was assessed using the Strengthening the Reporting of Observation Studies in Epidemiology [STROBE] criteria [11]. The lead author extracted data for study settings, study period, design and purpose, selection of cases, methods, outcomes, and results. The information was independently checked against the full-text articles by the second author and an agreement was reached for the accuracy of all studies. Studies quality was assessed on a scale from 0 to 10 . For this review, studies score of $<60 \%$ was considered to have poor methodological quality and, therefore, were excluded. Thus, the final number of studies meeting our inclusion criteria was 25 [11].

\section{Data synthesis, analysis, and assessment of heterogeneity}

We considered two issues: incidence of delirium and risk factors for delirium during hospitalization by pooling data. We had a specific analysis plan for each of these issues. An odds ratio was estimated for most of the studies that compared the delirium group with the nondelirium group. We estimated the DerSimonian and Laird fixed and random effects pooled log odd ratio of all studies, conducted a $\chi$ test for heterogeneity, and calculated the $p$ statistic and its $95 \%$ uncertainty interval. This was also done for analysis of incidence rate ratios.

We used Comprehensive Meta-analysis software (version 2, Biostat, Englewood, NJ, USA) [12] to combine data across studies. A fixed-effects model was initially used in this systematic review because we found the homogeneity across the studies population. A random-effects model was applied only if statistical heterogeneity existed. We assessed statistical heterogeneity using the Cochran Q test and by calculating $\gamma$-squared and $p$ values $(p>75 \%$ were considered to indicate a high level of heterogeneity) [13]. When heterogeneity was substantial $(p>75 \%)$, we investigated sources of heterogeneity by determining the effect of important modi ers: sample details (type and quantity), study design and risk for bias, and effect of imputed data.

\section{Results}

Twenty-five studies met the inclusion criteria for review. The studies had a total of 4484 patients, with the mean age of the study participants ranging from 74.9 to 84 years. Most participants were female $(74.36 \%)$. Almost one-third of the studies $(n=8)$ excluded participants with cognitive impairment or delirium. The hip fracture studies that met the inclusion criteria are presented in Table 1.

Table 1. Incidence and risk factors of delirium in hip fracture surgery

\begin{tabular}{|c|c|c|}
\hline Study & Incidence & Factors \\
\hline Marcantonio et al. 2000 [14], N=126 & $41.3 \%$ & $\begin{array}{l}\text { Age*, gender*, cognitive and functional* impairment, } \\
\text { comorbidity }\end{array}$ \\
\hline Edlund et al. 2001 [15], & $49 \%$ & Age, gender*, dementia*, Parkinson*, previous \\
\hline $\mathrm{N}=101$ & $\begin{array}{l}30 \% \text { preop } \\
19 \% \text { Postop }\end{array}$ & $\begin{array}{l}\text { delirium*constipation* }{ }^{*} \text { creatinine* }^{*} \text {, depression, } \\
\text { anticholinergic agents*, Neuroleptic* }\end{array}$ \\
\hline Galanakis et al. $2001[16], N=105$ & $24 \%$ & $\begin{array}{l}\text { Age*, gender, cognitive*, vision*, hearing* impairment, } \\
\text { comorbidity, more than } 3 \text { prescribed drugs, sodium*, } \\
\text { potassium, depression*, low education*,psychotropic } \\
\text { drug use, number of medications }\end{array}$ \\
\hline Marcantonio et al. 2002 [17], N=122 & $40 \%$ & $\begin{array}{l}\text { Age, gender, cognitive*, functional impairment*, } \\
\text { comorbidity* }\end{array}$ \\
\hline $\begin{array}{l}\text { Zakriya et al. } 2002[18] \\
\mathrm{N}=168\end{array}$ & $28 \%$ & $\begin{array}{l}\text { Age, gender, health problem, sodium, BUN, creatinine, } \\
\text { albumin }\end{array}$ \\
\hline
\end{tabular}


Table 1. Incidence and risk factors of delirium in hip fracture surgery (Continue)

\begin{tabular}{|c|c|c|}
\hline Study & Incidence & Factors \\
\hline Morrison et al. 2003 [19], $N=541$ & $\begin{array}{l}16 \% \\
12 \% \text { preop } \\
14 \% \text { postop }\end{array}$ & $\begin{array}{l}\text { Age, gender, cognitive impairment, heart failure* } \\
\text { comorbidity, opioids*, meperidine*, poor controlled } \\
\text { pain* }\end{array}$ \\
\hline Kagansky et al. 2004 [20], N=102 & $12 \%$ & $\begin{array}{l}\text { Age, preexisting cognitive* and function impairment, } \\
\text { comorbidity, health problem*, more than } 4 \text { prescribed } \\
\text { drugs*, hemoglobin, WBC }\end{array}$ \\
\hline Zakriya et al. 2004 [21], N = 92 & $\begin{array}{l}28 \% \\
21 \% \text { preop } \\
28 \% \text { postop }\end{array}$ & \\
\hline Olofsson et al. 2005 [22], $N=61$ & $62 \%$ & $\begin{array}{l}\text { Age, male, vision, hearing impairment, dementia*, } \\
\text { antidepressant (anticholinergic agent), depression*, } \\
\text { poly medicine }\end{array}$ \\
\hline Santos et al. 2005 [23], N=34 & $56 \%$ & $\begin{array}{l}\text { Age, gender, dementia*, hemoglobin, health problem, } \\
\text { opioids*, midazolam*, length of stay }\end{array}$ \\
\hline Sharma et al. 2005 [24], $N=47$ & $36 \%$ & health problem* \\
\hline Furlaneto \& Garcez-Leme 2006 [25], & $13 \%$ & Age, gender, cognitive* and functional impairment, \\
\hline $\mathrm{N}=103$ & $\begin{array}{l}17 \% \text { preop } \\
13 \% \text { postop }\end{array}$ & $\begin{array}{l}\text { health problem*, comorbidity, malnutrition, hemoglobin, } \\
\text { creatinine, education level }\end{array}$ \\
\hline $\begin{array}{l}\text { Goldenberg et al. } 2006[26] \\
\mathrm{N}=77\end{array}$ & $48 \%$ postop & $\begin{array}{l}\text { Age*, pre-existing cognitive* impairment, multiple } \\
\text { medications*, hematocrit*, albumin* }\end{array}$ \\
\hline $\begin{array}{l}\text { de Jonghe et al. } 2007[27] \\
N=101\end{array}$ & $16 \%$ & $\begin{array}{l}\text { Age, gender*, cognitive* and vision* impairment, health } \\
\text { problem*, BUN/Cr ratio, anticholinergic agent } \\
\text { (haloperidol) }\end{array}$ \\
\hline $\begin{array}{l}\text { van Munster et al. } 2008 \text { [28], } \\
\mathrm{N}=98\end{array}$ & $50 \%$ & $\begin{array}{l}\text { Age, gender, cognitive*, function* impairment, } \\
\text { polymedicine, Il-6*,IL-8*,Il-12*, length of stay }\end{array}$ \\
\hline van Munster et al. 2009 [3], N=120 & $52 \%$ & $\begin{array}{l}\text { Age, gender, cognitive*,physical impairment, } \\
\text { polymedicine, IL-6,IL-8, length of stay }\end{array}$ \\
\hline Juliebo et al. 2009 [29], N=364 & $\begin{array}{l}58 \% \\
21 \% \text { preop } \\
36.4 \% \text { postop }\end{array}$ & $\begin{array}{l}\text { Age, gender*, cognitive*, function*impairment, } \\
\text { comorbidity, health problem, BMI*, hemoglobin* } \\
\text { sodium, potassium, BUN/Cr ratio, polypharmacy*, } \\
\text { Arrhythmia, medication use (psychotropic, selective } \\
\text { serotonin reuptake inhibitor, zopiclone, aspirin, beta- } \\
\text { blocker, diuretic, statin) fentanyl* }\end{array}$ \\
\hline Juliebo et al. 2010 [30], $N=331$ & $43.2 \%$ & \\
\hline Kat et al. $2011[31], N=603$ & $12.3 \%$ postop & \\
\hline Bisschop et al. 2011 [32], $N=143$ & $34 \%$ & $\begin{array}{l}\text { Age*, gender, preexisting cognitive* and functional* } \\
\text { impairment, comorbidity*, laboratory abnormalities*, } \\
\text { glucose }\end{array}$ \\
\hline Lee et al. 2011 [33], $N=232$ & $30.2 \%$ & Age, gender, comorbidity, health problem*, BMI \\
\hline $\begin{array}{l}\text { Vochteloo et al. } 2011[34], N=378 \\
\text { drug use*, length of stay* }\end{array}$ & $27 \%$ & Age*, gender*,dementia, health problem*, psychotropic \\
\hline Sieber et al. $2011[35], N=236$ & & Age, gender*, dementia*, comorbidity*, opioids \\
\hline Witlox et al. 2011 [36], $N=76$ & $40 \%$ & Age*, cognitive* and functional impairment \\
\hline Nie et al. 2012 [37], $N=123$ & $13 \%$ & Age, gender, cognitive impairment, education \\
\hline
\end{tabular}

\footnotetext{
*Statistically significant $p<0.05$
} 


\section{Quality of the studies}

It was considered that $11 \%$ (4/37) were of high level of quality, $57 \%$ (21/37) were moderate level, and $32 \%$ (12/37) were low level. For internal validity, over half of the studies had unclear information regarding how the sample size was determined or if outcomes were objective. Almost all studies failed to describe any efforts to address sources of bias. Some studies used invalidated methods to describe delirium or terms such as 'confusional state' without a clear definition of term. Furthermore, studies did not check for statistical violation, such as a normal distribution or linear relationships. Sixty-seven percent of the studies used measurements whose validity had been previously reported. More than $40 \%$ did not provide diagnostic criteria of delirium. In relation to the analysis, almost all of the studies used logistic linear and/or linear regressions. Only a few studies reported how they handled missing data. Most studies failed to exclude confounders that might have a signiucant inuuence on predicting incidence of delirium. An issue for the meta-analysis showed the evidence of heterogeneity in incidence of delirium and cognitive impairment ( $p>75 \%)$. The sources of heterogeneity might be the result of a wide range of sample size, exclusion or inclusion of elderly with cognitive impairments, and methods of data collection. For example, the hypoactive form of delirium in patients with cognitive impairment was often overlooked in studies. Moreover, the variation may be explained by the difficulty in diagnosing delirium in the presence of cognitive impairment whereas when cognitive ability is intact, it is easier to recognize symptoms of delirium. Therefore, some episodes of delirium and the effect of risk factors might have been estimated inaccurately.

\section{Delirium assessment}

The most widely-used general diagnostic test was the Confusion Assessment Method (CAM) [38], which is a standard screening protocol consisting of an orientation-memory-concentration test and a delirium algorithm. However, the current 'gold standard' for assessing delirium are the diagnostic criteria set by the Diagnostic and Statistical Manual of Mental Disorders, 4th edition (DSM-IV) [39]. Other less commonly used diagnostic tools that feature different use of DSM criteria include the Organic Brain Syndrome Scale (OBS scale) [40] and the Delirium Symptom Interview (DSI) [41]. Severity scales designed for use by experts with significant professional training were the delirium Rating Scale (DRS-R-98) [42] and Memorial Delirium Assessment Scale (MDAS) [43]. Screening scale developed by nurses are the Delirium Observation Screening Scale (DOS) [44] and The NEECHAM Confusion Scale (NEECHAM) [45]. Bearing this in mind, all of the studies reviewed used one or more of these tools to define delirium and identify patients for studying.

\section{Incidence of delirium in elderly with hip fracture during hospitalization}

In elderly patients with a hip fracture, the incidence of delirium was $32.4 \%(95 \%$ CI $=25$. $9 \%-39.5 \%)$ with significant heterogeneity $(p<0.001)$. The incidence of delirium in the sample including cognitive impairment was $35.2 \%(95 \% \mathrm{CI}=27.7 \%$ $43.5 \%, p<0.001)$ and the incidence of delirium in the sample excluding cognitive impairment was $24.7 \%$ $(95 \%$ CI $=15.8 \%-36.4 \%, p<0.001)$. The reported incidence of preoperative delirium was $19.2 \%(95 \%$ $\mathrm{CI}=13.7 \%-26.3 \%, p<0.001)$ and the postoperative delirium was $22.3 \%(95 \% \mathrm{CI}=13.9 \%-33.7 \%$, $p<0.001$ ).

\section{Risk factors}

The etiology of delirium is usually multifactorial [48]. It can, however, be caused by a single factor. The review of 25 studies identified 12 risk factors of delirium, which are classified into two groups: predisposing and precipitating factors. The predisposing factors included age, gender, the impairment of cognition, function, and sensory impairment (vision and hearing), comorbidity, health problems, more than three prescribed drugs, and malnutrition. Precipitating factors were laboratory abnormalities, anemia and hypo- or hypernatremia, depression, and drugs (opioids and anticholinergic). Ten of twelve different risk factors were proven to have significant pooling of results. However, deficient nutrition as defined by albumin level and body mass index and sensory impairment were not statistically significant when data was pooled.

The results indicated that each year of age increases the risk for delirium, with effect size (ES) $1.06(95 \% \mathrm{CI}=1.03-1.09, p<0.001)$. Men were at a higher risk than women. Men with hip fracture were 1.34 times more likely to face delirium than women with hip fracture $(95 \% \mathrm{CI}=1.08-1.68, p=0.01)$. Patients with dementia and cognitive impairment had 2.90 times more delirium than those who were 
cognitively intact $(95 \% \mathrm{CI}=1.91-4.42, p<0.001)$. The review indicated that functional impairments such as ambulatory and walking impairment, lower Activity Daily Living (ADL), and Instrument Activities of Daily Living (IADL), significantly increased risk factors for delirium $(\mathrm{ES}=1.75,95 \% \mathrm{CI}=1.39-2.20, p<0.001)$. Patients who had a greater number of comorbidities were more likely to have delirium ( $E S=1.59,95 \%$ $\mathrm{CI}=1.30-1.96, p<0.001)$. Health problems were also identified as being significantly predictive of delirium, with $\mathrm{ES}=2.64(95 \% \mathrm{CI}=2.04-3.42$, $p<0.001)$. More than three prescribed drugs also significantly increased risk factors for delirium $(\mathrm{ES}=1.28,95 \% \mathrm{CI}=1.10-1.49, p<0.001)$.

Among the three precipitating factors, nine laboratory blood values were tested as possible risk factors for delirium. Hypo- or hypernatremia $(\mathrm{ES}=1.73,95 \%$ CI $1.14-2.64, p=0.01)$ was the only one reported as significant risk factors. Drugs including anticholinergic agents, levodopa, hypnotics, and sedatives were noted to be a precipitating risk factor in developing delirium. The probability of developing delirium among patients who received anticholinergic drugs was more than two times that of nonusers $(\mathrm{ES}=2.01,95 \% \mathrm{CI}=1.60-2.75$, $p<0.001$ ). The administration of opioids (morphine and meperidine) also influenced the presence of postoperative delirium $(\mathrm{ES}=2.13,95 \% \mathrm{CI}=1.42$ $3.18, p<0.001)$. When meperidine and morphine were compared, the findings indicated that patients receiving meperidine had a higher risk of delirium than those receiving morphine $(\mathrm{RR}=1.93,95 \% \mathrm{CI}=1.27$ $2.94, p<0.001)$. We also found that the elderly who were depressed at the time of hip fracture are at 4 times higher risk for delirium than those who were not depressed with $\mathrm{ES}=4.07(95 \% \mathrm{CI}=1.95-8.49$, $p<0.001)$.

\section{Discussion}

Delirium is a common and serious condition among the elderly, particularly in hospitalized patients with hip fracture. We found that the incidence of delirium after hip fracture ranged from $25.9 \%$ to $39.5 \%$. The variance can be explained by methodological differences and measurement tools used in previous studies. The variable exclusion criterion used reflects the large differences in the incidence of delirium. We found studies that excluded patients with cognitive dysfunction and had lower incidences of delirium than other studies that did not exclude them ( $25 \%$ vs. $35 \%$ ).
The results supported the hypothesis that delirium is difficult to diagnose among patients with cognitive dysfunction, but when excluding these patients, the incidence of delirium may only represent a minimum risk subjects given that high-risk patients have been excluded.

Our findings demonstrate convincing evidence of the predictive value of both predisposing and precipitating factors for delirium. The results of the studies included showing clinically important effects of similar magnitude. The risk factors for delirium in the elderly with hip fracture were advanced age, male sex cognitive impairment, functional impairment, and history of comorbidity such as cardiovascular disease, congestive heart failure, and stroke. Depression, health status during admission, more than three prescribed drugs and using anticholinergic agents and opioids also were contributing factors. This analysis supports the hypothesis that delirium after surgery has procedurerelated and patient-related risk factors [46] that differ from those identified in geriatric studies [47]. In elderly patients with hip fracture who are highly vulnerable to delirium, such as those with dementia and multiple coexisting conditions, it may develop as a result of relatively benign insults, such as one dose of a sleeping medication or premedication. Conversely, in patients who are not vulnerable to delirium, it develops only after exposure to multiple noxious insults, such as major surgery and psychoactive medications. Addressing just one contributing factor is unlikely to resolve delirium in an older patients with hip fracture; all contributors should all be addressed when possible [6].

These findings have practical implications for management of elderly patients with hip fracture during hospitalization. However, one of the 10 risk factors influencing delirium - cognitive impairment — may be affected by heterogeneity. Health care providers are encouraged to use comprehensive assessment of the patient based on screening and identifying early signs of delirium. For example, careful reviews of prescribed drugs, laboratory testing, and identification of frail patients should be completed. This should make it possible to prevent delirium and treat patients [16, 27]. Specific screening should be incorporated in admission evaluation. The patients at high risk should also be monitored closely and consistently for early signs of delirium [48].

Based on these findings, minimizing time spent in bed should be promoted. Mobilization should be implemented as soon as possible. Attempts should be 
made to provide a comfortable and familiar environment such as a quiet, well-lit room with easilyvisible clocks and a calendar. The patients' awareness and interaction with the environment should be optimized through use of visual aids, hearing aids, and frequent reorientation. Prescribed drugs should be reviewed with avoidance where possible of anticholinergic agents. Meperidine should be avoided or used sparingly. The anticholinergic drugs include antipsychotics and sedative-hypnotics. They should be reduced or replaced with medications that have no central effects. Particularly, reduction of antiParkinson drugs should be conducted in close collaboration with the Parkinson's team. The adoption of a standardized protocol for pain assessment and management, appropriate fluid replacement and nutrition are needed to prevent electrolyte imbalances. Consideration should be made for geriatric and psychiatric consultation to evaluate and treat of cognitive impairment, depression and comorbidity when indicated.

Our study has limitations and strengths. First, the heterogeneity in risk factors such as cognitive impairment could be explained by different time of delirium assessment, which included or excluded cognitive impairment during recruitment. Second, it is important to keep in mind that most participants were selected from one unit or one hospital, in a teaching institution. It is therefore possible that these patients had more complicated cases. Thirdly, results were not adjusted for confounders known to influence delirium development. As a result, our studies may overestimate the incidence of delirium in elderly patients with hip fracture. Despite these limitations, our study provides useful information to understand incidence and associated risk factors in elderly hip fracture patients with and without delirium. We included the most commonly investigated risk factors influencing care. Finally, this information may help facilitate the most effective strategy for reducing incidence by orientation protocols, better fluid balance, mobility enhancement, better selection and dosing of pain medications.

\section{Acknowledgment}

This research received no specific grant from any funding agency in the public, commercial or not-forprofit sectors. No conflict of interest has been declared by the author.
The authors would like to acknowledge Yupin Aungsuroch, PhD, Associate Professor, and Chanokporn Jitapanya, PhD, Chulalongkorn University, Faculty of Nursing for all their help and inspiration.

\section{References}

1. Bitsch M, Foss N, Kristensen B, Kehlet H. Pathogenesis of and management strategies for postoperative delirium after hip fracture: a review. Acta Orthop Scand. 2004; 75:378-89.

2. American Psychiatric Association practice guideline for the treatment of patients with delirium. Am J psych. 1999; 156(5 Suppl):1-20.

3. van Munster BC, Korse CM, de Rooij SE, Bonfrer JM, Zwinderman AH, Korevaar JC. Markers of cerebral damage during delirium in elderly patients with hip fracture. BMC Neurology. 2009; 9:21-8.

4. U.S. Department of Health and Human Services. CMS Pub. No. 03445. Washington, DC: Centers for Medicare and Medicaid Services; 2004. CMS Statistics; p. 34 .

5. Inouye SK, Charpentier PA. Precipitating factors for delirium in hospitalized elderly persons. Predictive model and interrelationship with baseline vulnerability. JAMA. 1996; 275:852-7.

6. Inouye SK, Foreman MD, Mion LC, Katz KH, Cooney LM Jr. Nurses' recognition of delirium and its symptoms: comparison of nurse and researcher ratings. Arch Intern Med. 2001; 161:2467-73.

7. Yang FM, Inouye SK, Fearing MA, Kiely DK, Marcantonio ER, Jones RN. Participation in activity and risk for incident delirium. J Am Geriatr Soc. 2008; 56:1479-84.

8. Michaud L, Bula C, Berney A, Camus V, Voellinger R, Stiefel F, et al. Delirium: guidelines for general hospitals. J Psychosom Res. 2007; 62:371-83.

9. Moher D, Liberati A, Tetzlaff J, Altman DG, The PRISMA Group (2009). Preferred Reporting Items for Systematic Reviews and Meta-Analyses: The PRISMA Statement. PLoS Medicine. 2009; 6:e1000097

10. Richardson W, Wilson M, Nishikawa J, Hayward R. The well-built clinical question: a key to evidencebased decisions. ACP Journal Club. 1995; 123:A12-3.

11. Vandenbroucke JP, von Elm E, Altman DG, Gotzsche PC, Mulrow CD, Pocock SJ, et al. Strengthening the Reporting of Observational Studies in Epidemiology (STROBE): explanation and elaboration. Epidemiology. 2007; 18:805-35.

12. Borenstein M. Software for publication bias in publication bias in meta-analysis-prevention, 
assessment and adjustments. edited by H.R. Rothstein, A.J. Sutton and M. Borenstein. USA: John Wiley \& Sons; 2005.

13. Higgins JP, Thompson SG, Deeks JJ, Altman DG. Measuring inconsistency in meta-analyses. BMJ. 2003; 327:557-60.

14. Marcantonio ER, Flacker JM, Michaels M, Resnick NM. Delirium is independently associated with poor functional recovery after hip fracture. J Am Geriatr Soc. 2000; 48:618-24.

15. Edlund A, Lundstrom M, Brannstrom B, Bucht G, Gustafson Y. Delirium before and after operation for femoral neck fracture. J Am Geriatr Soc. 2001; 49: 1335-40.

16. Galanakis P, Bickel H, Gradinger R, Von Gumppenberg $\mathrm{S}$, Forstl H. Acute confusional state in the elderly following hip surgery: incidence, risk factors and complications. Int J Geriatr Psychiatry. 2001; 16: 349-55.

17. Marcantonio E, Ta T, Duthie E, Resnick NM. Delirium severity and psychomotor types: their relationship with outcomes after hip fracture repair. J Am Geriatr Soc. 2002; 50:850-7.

18. Zakriya KJ, Christmas C, Wenz JF Sr, Franckowiak S, Anderson R, Sieber FE. Preoperative factors associated with postoperative change in confusion assessment method score in hip fracture patients. Anesth Analg. 2002; 94:1628-32.

19. Morrison RS, Magaziner J, Gilbert M, Koval KJ, McLaughlin MA, Orosz G, et al. Relationship between pain and opioid analgesics on the development of delirium following hip fracture. J Gerontol A Biol Sci Med Sci. 2003; 58:M76-81.

20. Kagansky N, Rimon E, Naor S, Dvornikov E, Cojocaru $\underline{\mathrm{L} \text {, Levy S. Low incidence of delirium in very old }}$ patients after surgery for hip fractures. Am J Geriatr Psychiatry. 2004; 12:306-14.

21. Zakriya K, Sieber FE, Christmas C, Wenz JF Sr, Franckowiak S. Brief postoperative delirium in hip fracture patients affects functional outcome at three months. Anesth Analg. 2004; 98:1798-802.

22. Olofsson B, Lundstrom M, Borssen B, Nyberg L, Gustafson Y. Delirium is associated with poor rehabilitation outcome in elderly patients treated for femoral neck fractures. Scand J Caring Sci. 2005; 19: 119-27.

23. Santos FS, Wahlund LO, Varli F, Tadeu Velasco I, Jonhagen ME. Incidence, clinical features and subtypes of delirium in elderly patients treated for hip fractures. Dement Geriatr Cogn Disord. 2005; 20 :
231-7.

24. Sharma PT, Sieber FE, Zakriya KJ, Pauldine RW, Gerold KB, Hang J, et al. Recovery room delirium predicts postoperative delirium after hip-fracture repair. Anesth Analg. 2005; 101:1215-20.

25. Furlaneto ME, Garcez-Leme LE. Delirium in elderly individuals with hip fracture: causes, incidence, prevalence, and risk factors. Clinics (Sao Paulo). 2006; 61:35-40.

26. Goldenberg G, Kiselev P, Bharathan T, Baccash E, Gill L, Madhav V, et al. Predicting postoperative delirium in elderly patients undergoing surgery for hip fracture. Psychogeriatrics. 2006; 6:43-8.

27. de Jonghe JF, Kalisvaart KJ, Dijkstra M, van Dis H, Vreeswijk R, Kat MG, et al. Early symptoms in the prodromal phase of delirium: a prospective cohort study in elderly patients undergoing hip surgery. Am J Geriatr Psychiatry. 2007; 15:112-21.

28. van Munster BC, Korevaar JC, Zwinderman AH, Levi M, Wiersinga WJ, de Rooij SE. Time-course of cytokines during delirium in elderly patients with hip fractures. JAm Geriatr Soc. 2008; 56:1704-9.

29. Juliebo V. Risk factors for preoperative and postoperative delirium in elderly patients with hip fracture. JAm Geriatr Soc. 2009; 57:1354-61.

30. Juliebo V, Krogseth M, Skovlund E, Engedal K, Ranhoff AH, Wyller TB. Delirium is not associated with mortality in elderly hip fracture patients. Dement Geriatr Cogn Disord. 2010; 30:112-20.

31. Kat MG, de Jonghe JF, Vreeswijk R, van der Ploeg T, van Gool WA, Eikelenboom P, et al. Mortality associated with delirium after hip-surgery: a 2-year follow-up study. Age Ageing. 2011; 40:312-8.

32. Bisschop PH, de Rooij SE, Zwinderman AH, van Oosten HE, van Munster BC. Cortisol, insulin, and glucose and the risk of delirium in older adults with hip fracture. J Am Geriatr Soc. 2011; 59:1692-6.

33. Lee KH, Ha YC, Lee YK, Kang H, Koo KH. Frequency, risk factors, and prognosis of prolonged delirium in elderly patients after hip fracture surgery. Clin Orthop Relat Res. 2011; 469:2612-20.

34. Vochteloo AJ, Moerman S, van der Burg BL, de Boo M, de Vries MR, Niesten DD, et al. Delirium risk screening and haloperidol prophylaxis program in hip fracture patients is a helpful tool in identifying highrisk patients, but does not reduce the incidence of delirium. BMC Geriatr. 2011; 11:39-46.

35. Sieber FE, Mears S, Lee H, Gottschalk A. Postoperative opioid consumption and its relationship to cognitive function in older adults with hip fracture. J Am Geriatr 
Soc. $2011 ; 59: 2256-62$.

36. Witlox J, Kalisvaart KJ, de Jonghe FM, Verwey NA, van Stijn MF, Houdijk AP, et al. Cerebrospinal fluid $\mathrm{B}$-amyloid and tau are not associated with risk of delirium: a prospective cohort study in older adults with hip fracture. J Am Geriatr Soc. 2011; 59:1260-7.

37. Nie H, Zhao B, Zhang YQ, Jiang YH, Yang YX. Pain and cognitive dysfunction are the risk factors of delirium in elderly hip fracture Chinese patients. Arch Gerontol Geriatr. 2012; 54:e172-4.

38. Inouye SK, van Dyck CH, Alessi CA, Balkin S, Siegal AP, Horwitz RI. Clarifying confusion: the confusion assessment method: a new method for detection of delirium. Ann Intern Med. 1990; 13:941-8.

39. American Psychiatric Association. Diagnostic and statistical manual of mental disorders. $4^{\text {th }}$ edition text. Washington DC, American Psychiatric Association; 1994.

40. Gustafson L, Lindgren M, Westling B. The OBS scale-A factor analysis approach to evaluation of confusional states and other organic brain syndromes. Departments of Psychogeriatrics, Lund University 1995.

41. Albert MS, Levkoff SE, Reilly C, Liptzin B, Pilgrim D, Cleary PD, et al. The delirium symptom interview: an interview for the detection of delirium symptoms in hospitalized patients. J Geriatr Psychiatry Neurol.
1992; 5:14-21.

42. Trzepacz PT, Mittal D, Torres R, Kanary K, Norton J, Jimerson $\mathrm{N}$. Validation of the delirium rating scalerevised-98: comparison with the delirium rating scale and the cognitive test for delirium. J Neuropsychiatry Clin Neurosci. 2001; 13:229-42.

43. Breitbart W, Rosenfeld B, Roth A, Smith MJ, Cohen K, Passik S. The memorial delirium assessment scale. J Pain Symptom Manage. 1997; 13:128-37.

44. Schuurmans MJ, Shortridge-Baggett LM, Duursma SA. The delirium observation screening scale: a screening instrument for delirium. Res Theory Nurs Pract. 2003; 17:31-50.

45. Neelon VJ, Champagne MT, Carlson JR, Funk SG. The NEECHAM confusion scale: construction, validation, and clinical testing. Nurs Res. 1996; 45 : 324-30.

46. Inouye SK. Delirium in older persons. N Engl J Med. 2006; 354:1157-65.

47. Levkoff SE, Evans DA, Liptzin B, Cleary PD, Lipsitz LA, Wetle TT, et al. Delirium: the occurrence and persistence of symptoms among elderly hospitalized patients. Arch Intern Med. 1992; 152:334-403.

48. Schuurmans MJ, Duursma SA, Shortridge-Baggett LM, Clevers GJ, Pel-Littel R. Elderly patients with a hip fracture: the risk for delirium. Appl Nurs Res. 2003; 16:75-84. 